\title{
UCF'S EXEMPLARY FACULTY SUPPORT: AN INSTITUTIONALIZED ECOSYSTEM
}

\author{
Barbara E. Truman \\ Director, Course Development \& Web Services \\ University of Central Florida \\ Orlando, FL 32816-2810 \\ (407) 823-6624 \\ Fax (407) 823-3511
}

\begin{abstract}
The University of Central Florida was honored to receive the 2003 Sloan-C Excellence in Online Teaching and Learning Award for Faculty Development. The environment at UCF has doubled in the last ten years with the number of students, faculty, and developing campus locations. Rapid growth in brick and mortar on campus has not deterred the creation of a robust virtual campus where students and faculty interact essentially, but in different ways. Producing the faculty support architecture to achieve UCF's instructional potential as a metropolitan research university is a constant struggle for staff. This article describes the dynamic interplay of UCF's emerging ecosystem of institutionalized faculty support.
\end{abstract}

\section{KEY WORDS}

Faculty development, Online learning, Distributed learning, Instructional design, Faculty support, Professional development, Course development, Systems thinking, Learning organization

\section{INTRODUCTION}

The University of Central Florida (UCF), like most institutions in the United States, is engaged in online learning and has online programs available with more planned. What makes UCF unique in its online offerings is the systematic, designed support for faculty and online courses that have enabled so many faculty and students to engage. Forty four percent of UCF's students enrolled in at least one fully online (W) or reduced seat-time (M) course in the 2003-2004 academic year representing a $24.7 \%$ increase from the 2002-2003 academic year. Nearly 26\% of UCF's approximately 44,000 students enrolled in a fullyonline course in 2003-2004 representing a 20\% increase from the previous year. W and M courses represent $10 \%$ of all student credit hours offered at UCF, up from 8\% in 2002-2003 (Center for Distributed Learning Summary Report). Growth of the campus in enrollments and in location has been a challenge in itself. UCF hires over 100 new faculty each year and currently has 21 regional campus sites ranging in services and support staff availability.

Many institutions have faculty support personnel who provide instructional technology services to advance teaching and learning. Hundreds of workshops, classes, consultations, and institutes are conducted each year nationally to teach faculty what they need to know about online learning. What makes UCF's faculty support exemplary? How has UCF's exemplary faculty support helped define UCF as a metropolitan research university? 
From the onset in mid-1996, decisions were made to embrace online learning at UCF in a systematic versus ad hoc approach. Significant commitments of institutional support were assembled including organizational units, instructional design authority, course development production support, and assessment. Support was focused on departments and colleges prepared to plan for program development versus individual courses. Not all colleges have historically participated in UCF's online initiatives at the fullest levels, but all colleges and departments have had the opportunity to make their needs known. Each semester, through the facilitation of the Center for Distributed Learning, meetings are held with key staff to review how support is structured and how colleges can take advantage of available funding support.

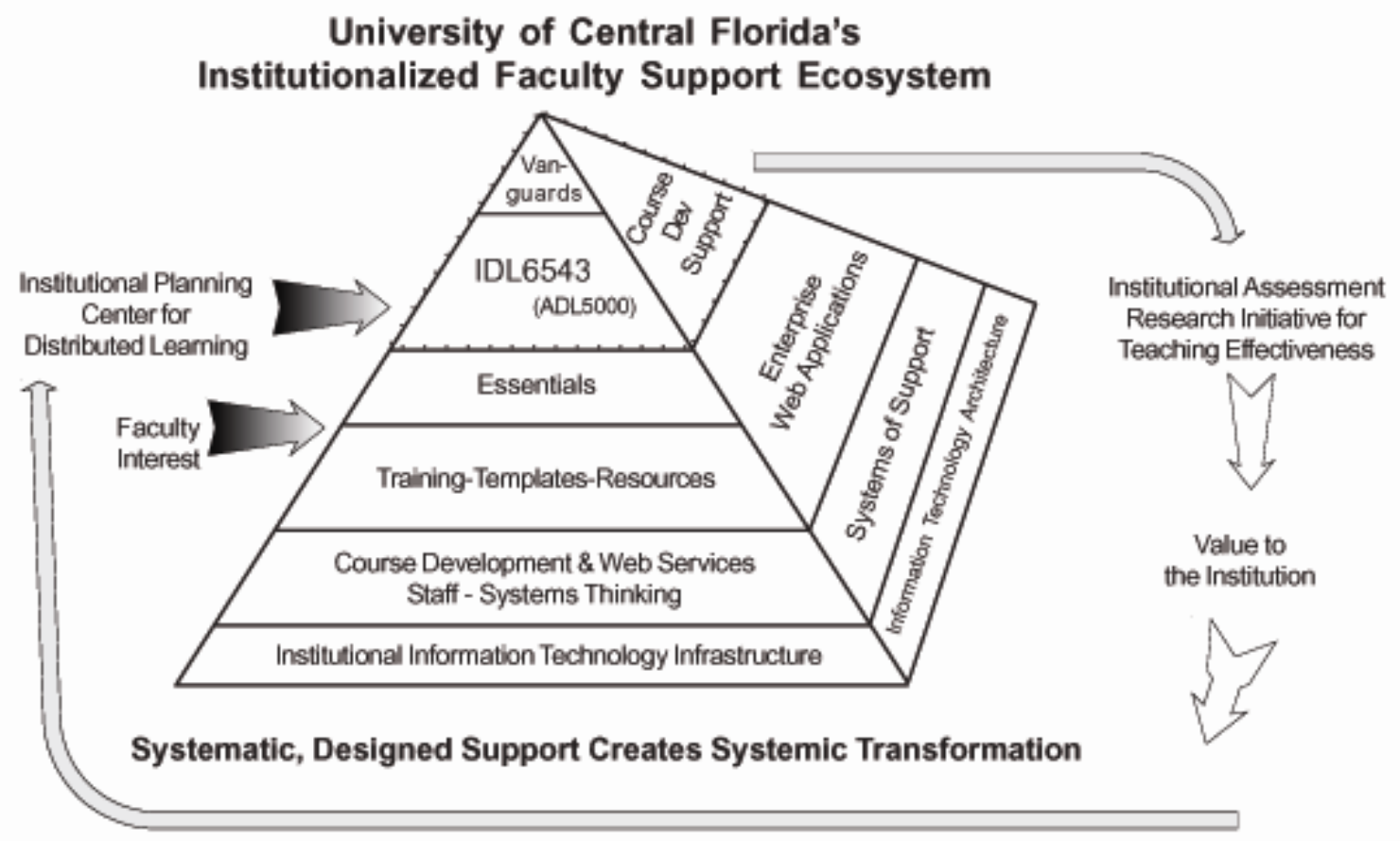

Diagram 1: UCF's Organizational Structure for Institutional Support

The cycle of planning and assessment illustrated in diagram 1 show how a hierarchy of systematic, faculty support exists at UCF to create a systemic, complex ecosystem. The resulting community of faculty participants transforms institutional culture providing an emerging framework for a metropolitan university with dual programs offered both face to face and online. The pyramid represents how the Web is embraced for meeting both instructional and institutional goals. The adjoining sides of the pyramid correspond in relation to their sides as shown.

What are the components of UCF's exemplary faculty support ecosystem and how do they interact? Primarily, three units within the Division of Information Technologies and Resources make up the deliberate interplay of faculty support. These units are the Center for Distributed Learning (CDL) http://distrib.ucf.edu, Course Development \& Web Services (CDWS) http://cdws.ucf.edu and the Research Initiative for Teaching Effectiveness (RITE) http://pegasus.cc.ucf.edu/ rite. All three units were formed in response to UCF's deliberate entry into the online arena of program development. The interplay among these units provides the advancement and stability of UCF's rapidly growing online initiatives. UCF's online initiatives and the comprehensive support required to maintain them are fully funded from internal sources. 


\section{INSTITUTIONAL PLANNING AND ASSESSMENT: UCF'S CYCLE FOR ONLINE PROGRAM DEVELOPMENT}

Every semester, the Center for Distributed Learning schedules planning sessions with the deans of all UCF's colleges to review online activity and plan future online programs. Besides planning, CDL has responsibility and funding to allocate incentives for online program development and monitor the success of these allocations. Current incentive packages include a notebook computer and \$2,000. The support package also implies support from CDWS staff in the average amount of \$3,000 initially. RITE also affords faculty participants the opportunity for research project collaboration on the scholarship of teaching within the discipline. As expected, colleges vary in the level of participation in planning. Some colleges having subordinates represent their dean, and some deans attend with many department chairs involved. Holistic data in the forms of enrollments, course types and trends across campus are shared in semesterly planning meetings to inform decision-making. When planning works at its best, colleges express needs in terms of actual programs and faculty ready to engage in UCF's sanctioned process for online program development. Readiness means that schedules have been considered enabling faculty to attend Friday sessions and have sufficient time to prepare an online course before the course is actually made available in the class schedule.

Not all colleges take advantage of institutional services provided to support faculty. Some colleges opt instead for autonomy and self-support. At UCF, the Center for Distributed Learning monitors this activity and makes certain that awareness for accreditation requirements are known. CDL ensures that proper forms are signed by colleges owning responsibility for faculty and student support and success when institutionally sanctioned processes are bypassed. To date independent college and departmental activity have been very low.

CDWS' role in UCF's Faculty Support Ecosystem is to create capacity for online success with a comprehensive strategy of focused support for priority development and broad, enterprise services that are efficient and effective. The top portion of the pyramid (see figure 2) outlined with dots indicate the activities where greatest staff resources, curriculum development, and process support are focused. Three times a year CDL provides CDWS a finalized list of faculty nominated by their deans. These faculty sign contract agreements for development and participation with CDWS to create their online courses. During the faculty and course development process, CDWS relies on CDL to maintain relationships with deans and department chairs to provide intervention if faculty have difficulties completing their agreements for course development. CDWS is freed to focus on conducting its award-winning faculty development process, IDL6543 described later.

Broad campus support for faculty development is achieved through more traditional means such as handson labs offered periodically during the year as training. CDWS also provides support for other faculty support units on campus such as the Faculty Center for Teaching and Learning and the Office of Instructional Resources for new faculty orientations, graduate teaching assistant training, and for interactive television (ITV) courses. CDWS was given responsibility for campus Web services to leverage the talent of production teams, but also to integrate alignment of all online support for students and faculty on and off campus. The duality of CDWS' mission, combined with a professional development emphasis enables opportunities such as the Essentials course described later for enterprise use of UCF's course management system.

The role of the Research Initiative for Teaching Effectiveness (RITE) is to provide campus support for faculty in the scholarship of teaching. RITE provides its most focused support each semester to faculty participating in that semester's IDL6543 faculty development course. RITE shares the latest findings 
regarding UCF's online initiative and recruits faculty to partner in research projects. Research support offers an attractive incentive to faculty and departments where pedagogical research is valued for tenure. Findings shared with faculty at the first IDL6543 class session include results from institutional surveys of perceptions and success and withdrawal rates from participating faculty and students. Another critical function of RITE is the analysis of institutional data mining efforts that articulate the value of the online initiative's impact on strategic planning. These data are shared with senior executives on regular basis for discussion and calibration of funding support and alignment with institutional goals. RITE's interplay within the ecosystem of faculty support summarizes the best and most current findings to inform planning at all levels: institutional, departmental, and operational. Drs. Chuck Dziuban and Patsy Moskal have been at the forefront of collecting and analyzing data as well as sharing results with organizations such as Sloan-C.

\section{HIERARCHICAL ELEMENTS OF UCF'S FACULTY SUPPORT ECOSYSTEM: THE PYRAMID}

\section{A. Institutional Information Technology (IT) Infrastructure and Architecture}

As a foundation of support, Computer Services and Telecommunications (CST), hosts UCF's Data Center including production servers and critical software applications. CST has responsibility for redundant, reliable and secure IT operations. The campus computing network, modem pools, campus computing labs, Help Desk, and most enterprise software applications are managed and maintained by CST. The staff of CST coordinate, plan, and implement an architecture for scaling and sustaining UCF's increasing dependencies on IT support.

\section{B. CDWS Staff and Systems of Support}

Course Development \& Web Services is freed from maintaining institutional IT needs. CDWS is also freed from institutional planning of online programs enabling its staff to focus on the creation of systems of support. Such systems are levers providing strategic faculty and professional development initiatives that can be scaled, sustained, often transferred to other staff, and reused. Homogenous and heterogeneous teams make up the ranks of CDWS staff. These teams employ systems thinking for work flow design of consistent, systematic support within a production environment made up of complex, multimedia project requiring varied expertise. We find that often the means to the end of the desired outcomes are more important than outcomes themselves. Thus the ability to replicate desired impact is most assured. As the multiplicity of multimedia production support increases, staff must embrace the value of community to fuel and inspire innovation and continued learning. CDWS operates on a guiding principle of facilitating community with professional development strategies that originate from instructional systems dynamics.

At the core of faculty support is the Instructional Design (ID) team. Members of the ID team are assigned to faculty as a filter determining support required by other CDWS teams' expertise. Instructional design team members are accountable for decisions made to support every faculty member's needs and their course needs. Consistency of support among faculty is achieved through team-based accountability enabling the ID team to shift faculty case loads if necessary providing redundant, reliable support. The authority of the instructional designers, combined with the systems of support from all CDWS teams, enable UCF to focus maximum institutional support on the faculty and courses deemed priorities.

CDWS is a full-service, multimedia production house employing graphic artists who make up the Digital Media Team, Flash and multimedia programmers who make up the New Media Team, video producers who make up the Video Convergence Team and student Web programmers called the Techrangers ${ }^{\mathrm{SM}}$. 
These experts combined with the authority of the Instructional Design Team, and systems of support create considerable capacity for institutional transformation through online learning.

Many institutions have similar staff capabilities found within CDWS in their Continuing Education (CE) departments. Most institutions with this type of organizational structure strive to weave capabilities of the outward-focused CE departments to benefit the inward-focused campus need. Clearly a balance is required not only of external online offerings, but of on-campus instructional technology support needs. CDWS staff struggle continuously with managing insatiable on-campus demands for enhanced online course development support. A fine balance is required, but seems unattainable to manage the focus of online program development with regular instructional technology needs. Broad training opportunities are required and the trick is making them complimentary with operational plans. To sustain support of all online courses and programs critical mass must be maintained.

\section{Training-Templates-Resources}

Besides being agents of change assigned one-on-one with faculty, CDWS' Instructional Design Team also creates curriculum for training as a strategy for performance support. From the onset in 1996, the decision was made not to provide arbitrary consultation on demand. CDWS operates on an appointmentonly basis to schedule professional development offerings, production, and consultation support. This strategy has enabled staff to create more templates, tools, job-aides, and actually courses that provide more scalable, sustainable support options for the entire campus. The Instructional Design Team also develops learner support for online teaching and learning as best exemplified in the Teaching Online (http://teach.ucf.edu) and Learning Online (http://learn.ucf.edu) Web sites. Another guiding principle of CDWS is to create a continuum of self-help to full-service support for clients, where full-service is delivered under CDWS' terms to manage the balance of timing.

Examples of training include a program called the Extended Techranger ${ }^{\mathrm{SM}}$ Program for part-time student Web programmers for departments (http://reach.ucf.edu/ tra007), Web101 (http://reach.ucf.edu/ web101) for learning Dreamweaver, Vid101 for video creation (http://reach.ucf.edu/ vid101a), and WebCT Academy. Examples of resources include self help manuals and practice accounts and for templates available for faculty to use for materials not part of $\mathrm{M}$ or $\mathrm{W}$ online courses.

\section{Enterprise Web Applications}

CDWS has responsibility to maintain the course management system software (WebCT). Management of upgrades and support for all the campus uses including training for other units using WebCT for PeopleSoft training, campus orientations, advising, and grant activity require vigilant monitoring. Significant staff resources are dedicated to testing, upgrade planning, and management of course management system needs. UCF has also hosted WebCT accounts for several local community colleges and the University of South Florida in efforts to build community. CDWS also is responsible for the campus portal development and has been able to integrate several applications such as WebCT into the portal. As CDWS creates Web services for the campus such as electronic commerce and a home-built application called eCommunity, the entire campus may use these capabilities.

\section{E. Essentials}

Faculty and staff desiring the use of WebCT have the opportunity to learn the course management system in a fully-online, self-paced manner. The Essentials program (http://reach.ucf.edu/ essentials) has 
tutorials, a self-guided manual, and provides a practice account to master concepts. An instructional designer reviews and verifies participant success then a WebCT account is automatically created and certification is granted. CDWS' Essentials course is the institutional entry point for all faculty wishing to use WebCT with the exception of the College of Engineering and Computer Science, which assumes all college support for WebCT.

\section{F. IDL6543 and ADL5000}

The first faculty development efforts to create online courses began in 1996 and evolved into an elaborate program conducted each semester at UCF. IDL6543 is the name of a course, (Interactive Distributed Learning for Technology-Mediated Course Delivery), but it is much more. IDL6543 is a production, complete with cast, characters, storyline and desired outcomes. Modeled as a reduced-seat time M course, IDL6543 blends four aspects that add up to a faculty development experience where $444 \equiv$ ulty have successfully completed the course. Face to face class meetings, online modules (with homework and quizzes), hands-on labs, and face to face consultations (with an assigned instructional designer) make up the IDL6543 experience. When faculty are selected and contracted with CDL, the ID Team determines who from among the team will be assigned to participants. The ID Team has a script of roles and tasks that must be performed to successfully pull off the experience. The Team meets each week for a skull session before the face to face class session and afterwards for a debriefing to review progress. Challenges occurred along the way in delivering IDL6543, especially when dedicated facilities did not exist, but now the routine is well-rehearsed and down pat. CDWS' production teams are poised, ready for the onslaught of graphic requests and Web pages needed to create the modules faculty prepare in the IDL6543 class. At the end of the eight weeks, a memorable showcase event is hosted complete with theme and costume to celebrate the faculty presentations of their developed modules. Presentations are video taped and streamed for later review by department chairs and deans who could not attend.

Each semester as time permits, multimedia components are added to IDL6543, but the online curriculum has not changed significantly since 1997. The training needs for hands on labs require the most updating. The processes used by the ID Team also have evolved to integrate the use of home grown software for relationship management and work flow tracking. IDL6543 enables faculty to participate as a cohort and a community evolves within three weeks. A community of faculty are far less likely to be paranoid about intellectual property infringements and are quicker to adopt innovations with their peers. Creativity unfolds and flows though the various disciplines of faculty involved in IDL6543 that semester. The greatest benefit of IDL6543 is that mainstream faculty are accommodated to allow the development of online programs instead of courses. The pixie dust that makes IDL6543 work so well is the qualities of the individual instructional designers who create one-on-one relationships with faculty based on mutual trust and respect.

ADL5000 (Advanced Distributed Learning) was created as a need from faculty who created courses within IDL6543 and after time were needed by their departments for other assignments. Adjunct replacements or teaching assistants were required to take over produced courses. Training was needed to teach adjunct faculty to facilitate the previously designed, online courses. ADL5000 is offered fully online and does not provide support to create or make significant modifications to these courses. CDWS struggles to manage the demand for IDL6543 and the increasing need for ADL5000. The Instructional Design Team also struggles with the inevitability of human behavior among faculty who wish to change the courses to suit their teaching style. ADL5000 is ripe for evolving into a new model of faculty support. 


\section{G. Course Development Support}

CDWS is both a service and product organization. Clients are expected to know how to use and apply the technologies and models proposed. Combining production support in the form of course development (coding Web materials, creating graphics, shooting photography) along with professional development has yielded best results in adoption of best practice. In most cases, only faculty participants or graduates of IDL6543 receive course development and production support.

CDWS values the means to the end as well as the end. Staff employ systems thinking that create systems of support. As support systems and processes are articulated they become exportable. Other organizations with similar responsibilities may buy into support processes much like using libraries of macros when writing or engaging in Open Source software development. As a metropolitan research university, UCF values partnerships. In 2001, CDWS had the opportunity to collaborate and provide assistance to the Naval Postgraduate School (NPS) in establishing their capacity to support online courses. An instructional designer from UCF was sent to NPS for three months and a similar IDL6543 course process was conducted with an emerging environment of support. Similar ventures have been conducted with Lake Sumter Community College located about 60 miles from UCF where CDWS' ID team traveled onsite to conduct IDL6543 with a vastly different support model. These experiments in collaboration, among highly differing institutional settings, have informed CDWS staff on the value of our systems of support.

\section{H. Vanguards}

CDWS is ready to employ a highly specialized program of support for advancing next-generation, online learning called the Vanguard Program. Faculty who have demonstrated interest and aptitude (preferably who have completed IDL6543) apply and are selected by CDWS to create prototype instructional applications that show promise to become models themselves. In the CDWS hierarchy of support, Vanguards receive the highest level of support in the form of a dedicated production team made up of at least an instructional designer, graphic artist, new media producer, and Web programmer. Our goal is to create commercially-viable courseware as a result of such investments. In our experience, faculty rarely have sufficient time to develop and teach their standard online courses where computer-mediated communication (CMC) is employed. These CMC courses account for approximately 95\% of UCF's online courses. Rare faculty will possess the motivational drive necessary to commit to the rigorous design necessitated with a dedicated team and project manager. To date, no institutional incentives have been associated with the Vanguard Program. Success independent of financial incentive has been achieved at various levels.

\section{SUMMARY}

The University of Central Florida has become exemplary for how a traditional, higher education institution can make the transition to offer both face to face and online programs with commendable results. Systematic and systemic support for faculty with strategically focused, institutionalized processes and talented faculty and staff have created a dynamic ecosystem. Like most institutions, UCF faces remarkable growth in uncertain funding possibilities at the state level. Investments in staff and planning have yielded award-winning faculty development programs that have helped transform the campus. The collaborative interplay among support units to specialize in their given roles along with sound assessment provide a compass for the future of the institution. 
Web Site Addresses

University of Central Florida

http://www.ucf.edu

Course Development \& Web Services (CDWS)

http://cdws.ucf.edu

Center for Distributed Learning (CDL)

http://distrib.ucf.edu

Research Initiative for Teaching Effectiveness (RITE)

http://pegasus.cc.ucf.edu/ rite

Faculty Development Initiatives

ADL5000 (for faculty taking over an existing online course)

http://reach.ucf.edu/ adl5000

Essentials (for faculty creating a web presence for their course)

http://reach.ucf.edu/ essentials

IDL6543 (for faculty developing an online course)

http://reach.ucf.edu/ idl6543

WebCT Academy (on-campus UCF classes)

Web Development Academy (on-campus UCF classes)

http://reach.ucf.edu/ webct411

http://reach.ucf.edu/ webdev

Related Resources

Learning Online Web Site

http://learn.ucf.edu

Teaching Online Web Site

http://teach.ucf.edu

Reach Server (online class listings, templates \& image vault)

http://reach.ucf.edu

Exemplary UCF courses

http://reach.ucf.edu/ well/exemplars

Web Development Resources

http://reach.ucf.edu/ wdr

\section{ACKNOWLEDGEMENTS}

My sincere thanks go to the staff of Course Development \& Web Services, who provide daily inspiration and courage to solve the dilemmas we find ourselves in while designing systems of support for UCF. Recognition would be lost without the continuous support from our friends in the Center for Distributed Learning, Research Initiative for Teaching Effectiveness and the unsung heroes of Computer Services who are always "on". Appreciation is also extended to UCF's senior executive leadership especially to Dr. Joel Hartman for his intense involvement in both ITs at UCF: information and instructional technology.

\section{ABOUT THE AUTHOR}

Barbara Truman is the director of Course Development \& Web Services at the University of Central Florida. As an instructional designer, she was hired in 1996 to create a faculty development program to begin UCF's foray into the delivery and support of online programs. Barbara previously worked with Dr. Steven Sorg (now Assistant Vice President and Director of UCF's Center for Distributed Learning) in 1995 on a Florida distance learning demonstration grant with the Central Florida Consortium of Higher Education. She and Dr. Sorg created UCF's first online course and were recruited to provide the collaboration necessary to operationalize UCF's institutional approach to online program development. Barbara received her bachelors and masters degrees from UCF where she has been an advocate for nontraditional students as a former single parent. Her research interests include collaboration assessment and change management. 